\title{
In vitro removal of toxic heavy metals by poly( $\gamma$-glutamic acid)-coated superparamagnetic nanoparticles
}

This article was published in the following Dove Press journal:

International Journal of Nanomedicine

9 August 2012

Number of times this article has been viewed

\author{
Baskaran Stephen Inbaraj' \\ Bing-Huei Chen ${ }^{1,2}$ \\ 'Department of Food Science, \\ ${ }^{2}$ Graduate Institute of Medicine, \\ Fu Jen University, Taipei, Taiwan
}

\begin{abstract}
Background: Chelation therapy involving organic chelators for treatment of heavy metal intoxication can cause cardiac arrest, kidney overload, mineral deficiency, and anemia.

Methods: In this study, superparamagnetic iron oxide nanoparticles (SPIONs) modified with an edible biopolymer poly ( $\gamma$-glutamic acid) (PGA) were synthesized by coprecipitation method, characterized and evaluated for their removal efficiency of heavy metals from a metal solution, and simulated gastrointestinal fluid (SGIF).
\end{abstract}

Results: Instrumental characterization of bare- and PGA-SPIONs revealed 7\% coating of PGA on SPIONs with a spherical shape and an iron oxide spinel structure belonging to magnetite. The particle sizes as determined from transmission electron microscopy images were 8.5 and $11.7 \mathrm{~nm}$ for bare- and PGA-SPIONs, respectively, while the magnetization values were 70.3 and $61.5 \mathrm{emu} / \mathrm{g}$. Upon coating with PGA, the zeta potentials were shifted from positive to negative at most of the environmental $\mathrm{pH}(3-8)$ and biological $\mathrm{pH}(1-8)$, implying good dispersion in aqueous suspension and favorable conditions for heavy metal removal. Batch studies showed rapid removal of lead and cadmium with the kinetic rates estimated by pseudo-second-order model being 0.212 and $0.424 \mathrm{~g} / \mathrm{mg} \cdot \mathrm{min}$, respectively. A maximum removal occurred in the $\mathrm{pH}$ range 4-8 in deionized water and 5-8 in SGIF corresponding to most gastrointestinal $\mathrm{pH}$ except for the stomach. Addition of different ionic strengths (0.001-1 M sodium acetate) and essential metals ( $\mathrm{Cu}, \mathrm{Fe}, \mathrm{Zn}, \mathrm{Mg}, \mathrm{Ca}$, and $\mathrm{K}$ ) did not show any marked influence on lead removal by PGASPIONs, but significantly reduced the binding of cadmium. Compared to deionized water, the lead removal from SGIF was high at all $\mathrm{pH}$ with the Langmuir monolayer removal capacity being $98.70 \mathrm{mg} / \mathrm{g}$ for the former and $147.71 \mathrm{mg} / \mathrm{g}$ for the latter. However, a lower cadmium removal capacity was shown for SGIF $(23.15 \mathrm{mg} / \mathrm{g})$ than for deionized water $(31.13 \mathrm{mg} / \mathrm{g})$.

Conclusion: These results suggest that PGA-SPIONs could be used as a metal chelator for clinical treatment of metal poisoning.

Keywords: superparamagnetic iron oxide nanoparticles, poly $(\gamma$-glutamic acid $)$, heavy metals, chelation therapy, gastrointestinal $\mathrm{pH}$, kinetics

\section{Introduction}

Numerous industrial activities and modern agricultural practices have led to the accumulation of toxic heavy metals in the human body via the food chain. Nonessential heavy metals such as lead, cadmium, mercury, arsenic, and aluminum are poisonous to cardiovascular, nervous, hematopoietic, immunological, and gastrointestinal systems. ${ }^{1-3}$ Additionally, they can cause kidney dysfunction, anemia, liver toxicity, cancer, and Alzheimer's disease. ${ }^{2-5}$ Because of chemical similarities, these heavy metals also act as effective competitors for essential metals and interact with several divalent
Correspondence: Bing-Huei Chen Department of Food Science, Fu Jen University, Taipei 242, Taiwan

Tel +88 6229053626

Fax +88 622905 I2I5

Email 002622@mail.fju.edu.tw 
metal transporters causing disruption of various physiological functions. ${ }^{2,3}$ Therefore, it is imperative to develop a potential and safe detoxifying agent for the treatment of metal intoxication.

Currently, chelation therapy involving organic chelators such as ethylenediaminetetraacetic acid (EDTA), meso-2, 3-dimercaptosuccinic acid, and British anti-lewisite is the preferred method for treatment of patients with heavy metal poisoning. ${ }^{6-8}$ Upon administration into the body, the organic chelators bind with heavy metals for eventual removal through the kidneys; however, these methods require multiple administrations, which may burden and damage the renal system during clearance of metal chelates from the body. ${ }^{9}$ In addition, these chelating agents are capable of binding to essential metals, resulting in severe mineral deficiency and anemia. ${ }^{10}$ For example, the occurrence of cardiac arrest due to hypocalcemia was reported in patients undergoing EDTA chelation therapy. ${ }^{11}$ Thus, developing an alternative solidphase adsorbent capable of selectively binding toxic heavy metals without affecting essential metals absorption would be therapeutically beneficial. Moreover, such solid-phase adsorbents administered orally would facilitate the removal of toxic metals from the gastrointestinal tract, resulting in their subsequent elimination through feces. ${ }^{9}$

Consequently, over a decade, dietary fibers from various food products such as rice bran, wheat bran, oat bran, and fruit fibers have been evaluated as alternatives to conventional organic chelators. ${ }^{12,13}$ Nevertheless, recent advancements in the field of nanoscience and nanotechnology have paved the way for the tailored synthesis of nanoparticles by coating or encapsulating them with functional materials. Iron oxide nanoparticles are particularly attractive as nanosorbents for toxin removal owing to their superparamagnetic behavior and large surface area. ${ }^{14-16}$ The advantages of superparamagnetic iron oxide nanoparticles (SPIONs) are low diffusion resistance, fast and efficient separation within a short time by employing a simple magnet, and they can be magnetically driven to the specific organs of application; ${ }^{14-16}$ but, they tend to aggregate in solution due to dipole-dipole, hydrophobic, and van der Waals interactions, limiting their application in various fields. ${ }^{16}$ To overcome this problem, iron oxide nanoparticles are often coated with a variety of functional materials such as surfactants or polymers, which has been well reviewed in the literature. ${ }^{16}$ More recently, several functionalized SPIONs were evaluated for removal of heavy metals, including chitosan-, humic acid-, dimercaptosuccinic acid-, oleic acid-, and polyrhodanine-functionalized SPIONs for lead, cadmium, mercury, copper, arsenic, chromium, and manganese. ${ }^{14,15,17-19}$ However, their application as possible metal chelators for clinical treatment of metal intoxication still remains to be explored.

In this study, we intended to synthesize poly $(\gamma$-glutamic acid) (PGA) functionalized SPIONs and evaluate their ability to remove heavy metals in vitro. The PGA is an edible and biodegradable natural biopolymer composed of numerous repetitive glutamic acid units connected by $\gamma$-peptide linkage, leaving the $\alpha$-carboxyl groups free for conjugation to a variety of compounds $\left(-\left[-\mathrm{NH}-\mathrm{CH}(\mathrm{COOH})-\left(\mathrm{CH}_{2}\right)_{2}-\mathrm{CO}-\right]_{n}-\right)^{20,21}$ It is extracellularly synthesized by Bacillus species, by either the de nova method through solid state fermentation, or by the salvage bioconversion method in submerged fermentation. ${ }^{20,21}$ Because of its unique $\gamma$-amide linkage, multifunctionality, and flexibility to be synthesized in different ionic forms ( $\mathrm{H}, \mathrm{Ca}, \mathrm{Na}, \mathrm{Mg}$, etc) with varying molecular weights (10,000 to 2 million Daltons), PGA finds wide application in many different fields such as food, medicine, agriculture, hygiene, cosmetics, and the environment. ${ }^{20,21}$ Our previous studies have demonstrated the efficiency of PGA as an adsorbent for the removal of heavy metals, organic dyes, and heterocyclic amines; ${ }^{22-25}$ however, the application of PGA-functionalized SPIONs for removal of heavy metals remains unknown. The objectives of this study were to synthesize, characterize, and evaluate the efficiency of PGASPIONs in removing heavy metals like lead and cadmium from both a metal solution and simulated gastrointestinal fluid.

\section{Materials and methods Materials}

Iron salts ferric chloride $\left(\mathrm{FeCl}_{3} \cdot 6 \mathrm{H}_{2} \mathrm{O}\right)$ and ferrous sulfate $\left(\mathrm{FeSO}_{4} \cdot 7 \mathrm{H}_{2} \mathrm{O}\right)$ for the synthesis of SPIONs were purchased from Nacalai Tesque (Kyoto, Japan); ammonium hydroxide $(28 \%, w / w)$ was procured from JT Baker (Phillipsburg, NJ); and hydrochloric acid was bought from Riedel de Haën (Seelze, Germany). The sodium form of PGA with low MW $(\sim 250 \mathrm{kDa})$ synthesized from Bacillus subtilis var Natto by a salvage bioconversion pathway in a submerged fermentation process was supplied by Vedan Enterprise Corporation (Taichung, Taiwan). An overhead mechanical stirrer (IKA ${ }^{\circledR}$ RW 20; IKA Works, Inc, Staufen, Germany) was used for vigorous stirring during the synthesis of SPIONs.

To prevent oxidation of iron salts during SPIONs synthesis, the milli-Q deionized water from EMD Millipore (Bedford, MA) was deoxygenated by bubbling $\mathrm{N}_{2}$ gas prior to use. The synthesized SPIONs were dried by using a vacuum incubator from Hong Sheng Instruments (Taipei, 
Taiwan). The nitrate salt of lead $\left(\mathrm{Pb}\left(\mathrm{NO}_{3}\right)_{2}\right)$ and sulfate salt of cadmium $\left(3 \mathrm{CdSO}_{4} \cdot 8 \mathrm{H}_{2} \mathrm{O}\right)$ used for metal removal experiments were from Sigma-Aldrich (St Louis, MO). Several other metal salts, namely, potassium chloride and magnesium(II) sulfate heptahydrate were purchased from Nacalai Tesque, Inc (Kyoto, Japan); copper(II) sulfate and zinc(II) sulfate heptahydrate were obtained from SigmaAldrich; calcium(II) chloride dihydrate was procured from JT Baker; and iron(II) sulfate heptahydrate was purchased from Ajax Finechem Pty Ltd (Sydney, Australia). Chemicals such as nitric acid, sodium hydroxide and, sodium bicarbonate used for adjusting the $\mathrm{pH}$ of both the metal solution and the simulated gastrointestinal fluid were obtained from Lab-Scan Analytical Sciences (Bangkok, Thailand), Nacalai Tesque, and Sigma-Aldrich, respectively. A neodymium-iron-boron (Nd-Fe-B) magnet from New Favor Industry Co, Ltd (Taipei, Taiwan) was used for decanting the SPIONs after both the synthesis and metal removal experiments. The chemicals used for preparation of the synthetic gastrointestinal fluid such as sodium chloride and 700 FIP U/g pepsin (a digestive enzyme) were bought from JT Baker and Merck and Co, Inc (Taipei, Taiwan), respectively.

\section{Syntheses of bare-SPIONs and PGA-SPIONs}

Syntheses of both bare- and PGA-SPIONs was based on a conventional co-precipitation method as described by Inbaraj et al. ${ }^{26}$ An aqueous mixture of $6.1 \mathrm{~g}$ ferric chloride and $4.2 \mathrm{~g}$ ferrous sulfate was prepared in deoxygenated deionized water, and a few drops of concentrated $\mathrm{HCl}$ were added for complete dissolution of iron salts. The mixture was then vigorously stirred at $2000 \mathrm{rpm}$ with simultaneous heating to $85^{\circ} \mathrm{C}$ and bubbling of nitrogen gas to prevent oxidation of ferrous ions. At $85^{\circ} \mathrm{C}, 14 \mathrm{~mL}$ of ammonium hydroxide were rapidly added to coprecipitate ferrous and ferric ions, and the color of solution eventually changed from light orange into black to produce SPIONs. For coating with PGA, $50 \mathrm{~mL}$ of $0.5 \mathrm{~g}$ NaPGA dissolved in deoxygenated deionized water was subsequently added, with stirring and nitrogen gas bubbling being continued for 1 hour at $85^{\circ} \mathrm{C}$. Upon completion of the reaction, the precipitated PGA-SPIONs were cooled at room temperature, followed by magnetic decanting of the supernatant fluid using a Nd-Fe-B magnet, washing several times with deoxygenated deionized water until the supernatant became neutral, and vacuum-drying at $0 \mathrm{~mm} \mathrm{Hg}$ and $40^{\circ} \mathrm{C}$ for 24 hours for further characterization. Bare-SPIONs were synthesized by adopting the same procedure as described above but without the addition of PGA, and the chemical reaction involved can be represented as:

$$
\mathrm{Fe}^{2+}+2 \mathrm{Fe}^{3+}+8 \mathrm{OH}^{-} \rightarrow \mathrm{Fe}_{3} \mathrm{O}_{4} \downarrow+4 \mathrm{H}_{2} \mathrm{O}
$$

\section{Characterization of bare-SPIONs and PGA-SPIONs}

Both bare- and PGA-SPIONs were characterized for the elucidation of PGA functionalization and percentage coating on SPIONs, as well as for structure, particle size, surface morphology, magnetic property, and surface charge at different solution $\mathrm{pH}$ levels. Fourier transform infrared spectroscopy (FTIR) of bare- and PGA-SPIONs were recorded on a Horiba FTIR spectrophotometer (FT 730; Horiba, Ltd, Kyoto, Japan) in the frequency range from $4000-400 \mathrm{~cm}^{-1}$ by mixing the sample with $\mathrm{KBr}$ crystals and pelletizing at a pressure of $150 \mathrm{~kg} / \mathrm{cm}^{2}$. An average of 32 interferograms at a resolution of $2 \mathrm{~cm}^{-1}$ was measured for each sample. For determination of structure, the X-ray diffraction (XRD) pattern was recorded on a Multiflex model Rigaku diffractometer (Rigaku; Multiflex, Tokyo, Japan) in the $2 \theta$ range of $20^{\circ}-70^{\circ}$ using $\mathrm{Cu}-\mathrm{K}_{\alpha}$ radiation $(\lambda=1.540556 \AA)$ at $40 \mathrm{kV}$ and $40 \mathrm{~mA}$. The mean particle size and surface morphology were determined by imaging bare- and PGASPIONs in a JEOL transmission field emission electron microscope (TEM, JEM 2100F; JEOL, Ltd, Tokyo, Japan) at $80 \mathrm{kV}$. Prior to imaging, a drop of diluted aqueous solution of each sample was spread on a 150 mesh copper TEM grid (Ted Pella Inc, Redding, CA) and vacuum-dried for 1 hour.

To determine the weight percentage of PGA coating on SPIONs, each sample weighing 5-15 mg was heated from $25^{\circ} \mathrm{C}-700^{\circ} \mathrm{C}$ in a versa Therm HS model Cahn thermogravimetric analyzer (Thermo Fisher Scientific Inc, Waltham, MA) at a heating rate of $10^{\circ} \mathrm{C} / \mathrm{min}$. Magnetization measurements of SPIONs were carried out at room temperature $(301 \mathrm{~K})$ in the applied magnetic field range from $+13,500$ to $-13,500$ Oe by employing a DMS 1660 model vibrating sample magnetometer (MicroSense, LLC, Lowell, MA). A Malvern Zetasizer Nano ZS (Malvern Instruments Ltd, Worcestershire, UK) was used for measuring the zeta potential of bare- and PGA-SPIONs by dispersing $0.1 \mathrm{~g} / \mathrm{L}$ of each sample in $0.001 \mathrm{M} \mathrm{NaCl}$ solutions adjusted to different $\mathrm{pH}$ values $(2,3,4,5,6,7$, and 8$)$. The concentration of synthesized SPIONs was determined by digesting samples at room temperature with sequential addition of concentrated $\mathrm{HCl}$ and concentrated $\mathrm{HNO}_{3}$ at a ratio of $2: 1(\mathrm{v} / \mathrm{v})$ and aspirating into a GBC 932 model flame atomic absorption spectrophotometer (FAAS; GBC Scientific Equipment Manufacturer Pty, Ltd, Melbourne, Australia) for iron analysis.

\section{Metal removal experiments and analysis}

Initially, $1000 \mathrm{mg} / \mathrm{L}$ stock solutions of lead and cadmium were prepared separately and diluted to desired working 
solutions of different concentrations by using deionized water. The metal removal experiments were carried out by taking $10 \mathrm{~mL}$ of each metal solution in a $20 \mathrm{~mL}$ glass vial and adjusting the solutions to a desired $\mathrm{pH}$ using a Suntex 701 pH meter (Suntex Instruments Co, Ltd, Taipei, Taiwan) coupled with a Horiba 9611-10D glass electrode (Horiba Instruments Inc, CA). Then, $0.5 \mathrm{~mL}$ of $0.2 \mathrm{~g} / \mathrm{L}$ PGA-SPIONs were added and shaken in a Firstek B601D reciprocating water bath shaker (Firstek Scientific Co, Tau-Yen, Taiwan) at $150 \mathrm{rpm}$ at $37^{\circ} \mathrm{C}$. After predetermined time intervals, the metal-loaded PGA-SPIONs were magnetically decanted using a Nd-Fe-B magnet, and the residual unbound metal in the solution was analyzed by FAAS. Control experiments were also performed to estimate the possible metal binding on the glass vials.

Initially, a hollow cathode lamp was inserted into a lamp socket in FAAS with wavelength, slit width, and lamp current set at $283.3 \mathrm{~nm}, 0.2 \mathrm{~nm}$ and $5 \mathrm{~mA}$ for lead and $228.8 \mathrm{~nm}$, $0.2 \mathrm{~nm}$, and $3 \mathrm{~mA}$ for cadmium, respectively. Air-acetylene gas mixture with an oxidizing flame at a ratio of 5:1 was employed. From respective stock solutions, four concentrations each of lead $(5,20,35$, and $50 \mathrm{mg} / \mathrm{L})$ and cadmium $(0.5,1,2$, and $3 \mathrm{mg} / \mathrm{L})$ were prepared for plotting calibration curves, and were then aspirated into FAAS after initial optimization of instrumental parameters. The levels of lead and cadmium in the supernatants obtained after magnetically decanting PGA-SPIONs were automatically determined based on the calibration curves.

\section{Metal removal at different $\mathrm{pH}$ levels}

To study the influence of solution $\mathrm{pH}$ on metal removal, $10 \mathrm{~mL}$ each of lead and cadmium solutions at $50 \mathrm{mg} / \mathrm{L}$ were adjusted to different $\mathrm{pH}$ values at 1, 1.5, 2, 2.5, 3, 3.5, 4, 5, 6, 7 , and 8 separately and shaken with $0.5 \mathrm{~mL}$ of $0.2 \mathrm{~g} / \mathrm{L}$ PGASPIONs for 2 hours at $37^{\circ} \mathrm{C}$. After 2 hours, the metal-loaded PGA-SPIONs were magnetically decanted for analyzing free lead and cadmium in the solution.

\section{Metal removal kinetics}

The kinetics of metal removal was studied by taking $10 \mathrm{~mL}$ each of the lead and cadmium solutions at $50 \mathrm{mg} / \mathrm{L}$, followed by adjusting $\mathrm{pH}$ to 5.5 , adding $0.5 \mathrm{~mL}$ of $0.2 \mathrm{~g} / \mathrm{L}$ PGA-SPIONs, and shaking the samples at $37^{\circ} \mathrm{C}$ for different time intervals of $1,2,3,5,10,30,60$, and 120 minutes. After each time interval, a portion of the sample was removed for magnetic decantation of metal-loaded PGA-SPIONs and the supernatant was eventually analyzed for lead or cadmium.

\section{Metal removal isotherms}

For developing binding isotherms, $10 \mathrm{~mL}$ each of lead and cadmium concentrations at 10, 20, 30, 40, 50, 60, 80, and $100 \mathrm{mg} / \mathrm{L}$ were adjusted to a $\mathrm{pH}$ level of 5.5. Next, $0.5 \mathrm{~mL}$ of $0.2 \mathrm{~g} / \mathrm{L}$ PGA-SPIONs was added and shaken for 2 hours at $37^{\circ} \mathrm{C}$. At equilibrium, the unbound metal in the solution was analyzed by FAAS after magnetically decanting the PGA-SPIONs.

\section{Metal removal at different ionic strengths}

Based on a method used by Yantasee et al, ${ }^{9}$ the effect of ionic strength in the biological matrix of metal removal by PGASPIONs was studied by spiking $50 \mathrm{mg} / \mathrm{L}$ of lead or cadmium solution in four different concentrations of sodium acetate (0.001, 0.01, 0.1, and $1 \mathrm{M}$ ) and mixing each with $0.5 \mathrm{~mL}$ of $0.2 \mathrm{~g} / \mathrm{L}$ PGA-SPIONs. The mixtures were then shaken for 2 hours at $37^{\circ} \mathrm{C}$, followed by magnetically decanting the metal-bound PGA-SPIONs for the analysis of free lead and cadmium in the solution.

\section{Lead or cadmium removal as affected by essential metals}

Selective removal of lead or cadmium by PGA-SPIONs in the presence of several biologically important essential metals was studied in a bisolute system by incorporating potassium, calcium, magnesium, zinc, iron or copper into the metal solution at a ratio of 1:1 (lead/cadmium:essential metal). The binary mixture of four different concentrations of lead or cadmium and each of the essential metals at 5, 25, 50 , and $100 \mathrm{mg} / \mathrm{L}$ was adjusted to $\mathrm{pH} 5.5$ and shaken with $0.5 \mathrm{~mL}$ of $0.2 \mathrm{~g} / \mathrm{L} \mathrm{PGA-SPIONs}$ at $37^{\circ} \mathrm{C}$ for 2 hours.

\section{Metal removal from simulated gastrointestinal fluid}

Simulated gastrointestinal fluid (SGIF) was prepared daily by adopting the procedure outlined by US Pharmacopeia for drug dissolution studies, ${ }^{27}$ and modifying the procedure based on a method described by Yantasee et al. ${ }^{9}$ The SGIF solution consisted of $0.03 \mathrm{M} \mathrm{NaCl}, 0.085 \mathrm{M} \mathrm{HCl}$, and $0.32 \%$ $(\mathrm{w} / \mathrm{v})$ pepsin. For evaluating the effectiveness of PGASPIONs towards the removal of lead or cadmium at different gastrointestinal $\mathrm{pH}, 50 \mathrm{mg} / \mathrm{L}$ lead or cadmium solution was spiked into SGIF solutions and adjusted to different $\mathrm{pH}$ values $(1,2,2.5,3,3.5,4,5,6,7$, and 8$)$ using $0.2 \mathrm{M}$ sodium bicarbonate. To each, $0.5 \mathrm{~mL}$ of $0.2 \mathrm{~g} / \mathrm{L}$ PGA-SPIONs was added, followed by shaking at $37^{\circ} \mathrm{C}$ for 2 hours, magnetically decanting the metal-bound PGA-SPIONs, and analyzing the supernatant for free lead or cadmium. In comparison with the isotherms obtained in deionized water, metal removal 
isotherms were also developed by preparing eight different concentrations $(10,20,30,40,50,60,80$, and $100 \mathrm{mg} / \mathrm{L})$ each of lead and cadmium in SGIF, adjusting to $\mathrm{pH} 5.5$, and adding $0.5 \mathrm{~mL}$ of $0.2 \mathrm{~g} / \mathrm{L}$ PGA-SPIONs. The mixtures were then shaken at $37^{\circ} \mathrm{C}$ for 2 hours, and the metal-laden PGASPIONs were magnetically decanted to analyze residual lead and cadmium in the solution.

\section{Data analyses}

Metal removal experiments were done in duplicate and the average values, which showed a maximum deviation of only $\pm 5 \%$, were used for calculation and modeling. Metal removal capacity $(\mathrm{q}, \mathrm{mg} / \mathrm{g})$ at different shaking times was determined based on the mass balance equation $\mathrm{q}=\left(\mathrm{C}_{\mathrm{i}}-\mathrm{C}\right)$ $(\mathrm{V} / \mathrm{W})$, where $\mathrm{C}_{\mathrm{i}}(\mathrm{mg} / \mathrm{L})$ is the initial metal concentration, $\mathrm{C}(\mathrm{mg} / \mathrm{L})$ is the metal concentration in solution after time $\mathrm{t}$ (min), V (L) is the volume of metal solution, and W $(\mathrm{g})$ is the weight of PGA-SPIONs. ${ }^{22,24}$ Likewise, metal binding at equilibrium can be calculated using the same equation described above by replacing $\mathrm{C}$ with $\mathrm{C}_{\mathrm{e}}$ and $\mathrm{q}$ with $\mathrm{q}_{\mathrm{e}}$, where $\mathrm{C}_{\mathrm{e}}$ and $\mathrm{q}_{\mathrm{e}}$ are the metal concentration $(\mathrm{mg} / \mathrm{L})$ in the solution and removal capacity $(\mathrm{mg} / \mathrm{g})$ at equilibrium, respectively. Modeling of experimental data on metal removal kinetics and isotherms were performed by a nonlinear regression method using a GNUPLOT software program (C) Thomas Williams and Colin Kelley, version 4.0 for Windows) through the Levenberg-Marquardt algorithm. ${ }^{22,24}$

\section{Results and discussion PGA functionalization and percentage coating}

The FTIR spectrum of bare-SPIONs revealed a sharp peak at $578.8 \mathrm{~cm}^{-1}$, which is typical of the Fe-O bond in iron oxide nanoparticles (Figure 1A). However, three distinctive peaks were shown for pure PGA corresponding to $\mathrm{C}=\mathrm{O}$ stretch of free carboxylic acids at $1633.4 \mathrm{~cm}^{-1}$, asymmetric $\mathrm{COO}^{-}$stretch and peak overlap of N-H/C-N deformation at $1578.2 \mathrm{~cm}^{-1}$, and symmetric $\mathrm{COO}^{-}$at $1400.9 \mathrm{~cm}^{-1} \cdot{ }^{26}$ After coating of PGA on SPIONs, peaks of both bare-SPIONs and pure PGA appeared in the spectrum of PGA-SPIONs, affirming the coating of PGA did occur on the surface of the SPIONs (Figure 1A).

The thermogravimetric analyzer curves depicted an initial small weight loss of $\sim 0.5 \%-1 \%$ caused by the removal of adsorbed water or surface hydroxyl groups (Figure 1B). However, at temperatures $>200^{\circ} \mathrm{C}$, the weight loss rose to $1 \%$ for bare-SPIONs and $8 \%$ for PGA-SPIONs. It is possible that the decomposition of amorphous iron hydroxides and the formation of iron oxide for bare-SPIONs and the evaporation followed by the decomposition of PGA coating for the PGA-SPIONs led to these results. Based on the relative comparison of weight loss curves of bare- and PGA-SPIONs, the amount of PGA coated on SPIONs was estimated to be $7 \%$ (Figure 1B).

\section{Structure and surface morphology}

The XRD pattern showed six characteristic diffraction peaks corresponding to the Bragg reflections (2 20$)$ at $30^{\circ},(311)$ at $35^{\circ},(400)$ at $43^{\circ},\left(\begin{array}{ll}4 & 2\end{array}\right)$ at $53^{\circ},(511)$ at $57^{\circ}$, and (4 40$)$ at $62^{\circ}$, implying that the iron oxide spinel structure is typical of either magnetite $\left(\mathrm{Fe}_{3} \mathrm{O}_{4}\right)$ or maghemite $\left(\gamma-\mathrm{Fe}_{2} \mathrm{O}_{3}\right)^{28}$ (Figure $\left.2 \mathrm{~A}\right)$. Nonetheless, the estimated lattice constant for bare-SPIONs (8.3945 $\AA$ ) and PGA-SPIONs (8.3925 $\AA$ ) was close to the standard value for magnetite $(8.3960 \AA)$ and not maghemite (8.3515 $\AA$ ), demonstrating that the synthesized SPIONs are mainly magnetite. A $1 \times 10^{5}$ magnified TEM image showed the morphology of both bare-SPIONs and PGA-SPIONs to be roughly spherical in shape, with the mean particle size determined by the particle size distribution histograms, being 8.5 and $11.7 \mathrm{~nm}$, respectively (Figure 2B).

\section{Magnetic property}

The magnetization curves obtained from vibrating sample magnetometer data at varying applied magnetic fields (H, Oe) illustrated a superparamagnetic behavior with zero coercivity or remanence, indicating that a high dispersibility at $\mathrm{H}=0$ and a high attractive force at $\mathrm{H} \neq 0$ may occur (Figure $3 \mathrm{~A}$ ). This phenomenon is particularly important for fast separation of metal-loaded PGA-SPIONs within a short time, and the driving of metals to specific organs or tissues by using a magnet. Based on the linear plot of magnetization moment versus $1 / \mathrm{H}$, the saturation magnetization (Ms) values were obtained by extrapolating the straight-line to zero magnetic field, and were $70.3 \mathrm{emu} / \mathrm{g}$ for bare-SPIONs and $61.5 \mathrm{emu} / \mathrm{g}$ for PGASPIONs (Figure 3B). However, the Ms value reported for bulk magnetite is relatively higher (89-92 emu/g), ${ }^{28}$ which may be attributed to the small-particle surface effect resulting from the large surface area to volume ratio of synthesized SPIONs. ${ }^{28,29}$ A drop in Ms value by $12.5 \%$ upon the coating of SPIONs with PGA confirmed the PGA coating on SPIONs. Nevertheless, an abundant magnetic property was still retained for PGASPIONs to provide fast separation using a magnet.

\section{Zeta potential, surface charge, and point of zero charge}

The zeta potentials measured in millivolts $(\mathrm{mV})$ as a function of different $\mathrm{pH}(2-8)$ revealed positive surface charge 

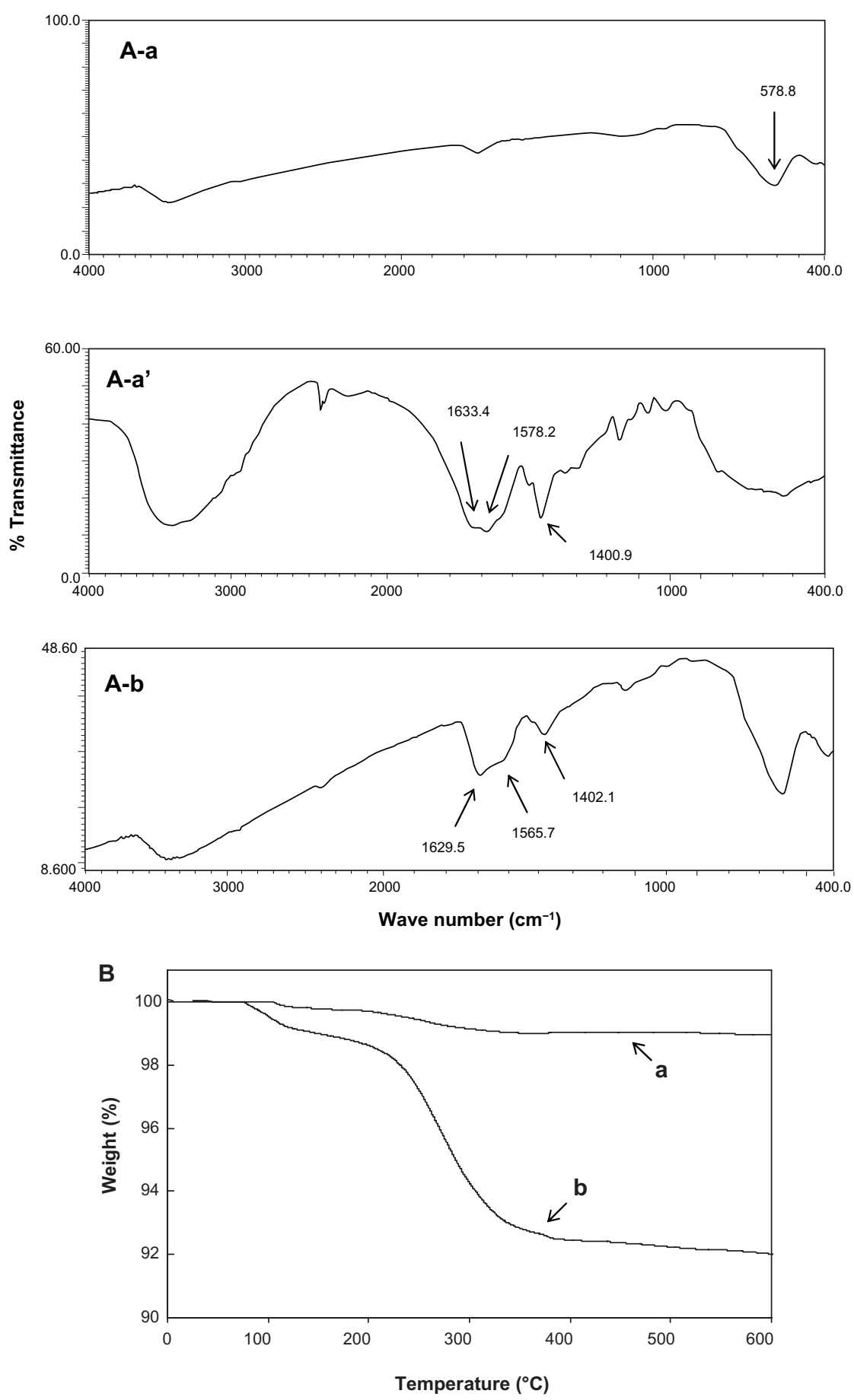

Figure I Comparative Fourier transform infrared spectra of bare-SPIONs. (A-a) Pure PGA (A-a') and PGA-SPIONs (A-b), as well as thermogravimetric curves of bareSPIONs (B-a) and PGA-SPIONs (B-b).

Abbreviations: SPIONs, superparamagnetic iron oxide nanoparticles; PGA, poly( $\gamma$-glutamic acid); PGA-SPIONs, poly $(\gamma$-glutamic acid)-superparamagnetic iron oxide nanoparticles.

for bare-SPIONs at most $\mathrm{pH}$ values (2-6), except for $\mathrm{pH} 7$ and 8 (Figure 4). Conversely, upon coating with PGA, an opposite trend was observed with the surface charge being negative at $\mathrm{pH} 3-8$ and positive at $\mathrm{pH} 2$. The cross-over point from positive to negative zeta potential denoting the $\mathrm{pH}$ of point of zero charge $\left(\mathrm{pH}_{\mathrm{PZC}}\right)$ was 6.8 for bare-SPIONs, which was similar to the reported value of $6.5 .{ }^{17}$ However, after the coating of PGA, the $\mathrm{pH}$ value declined to 2.4 amid the presence of abundant carboxylic acid groups. The low $\mathrm{pH}_{\mathrm{PZC}}$ of PGA-SPIONs indicated that their negative surface charges at most of the environmental $\mathrm{pH}$ (3-9) and biological $\mathrm{pH}(1-8)$ should prevent aggregation and facilitate the 

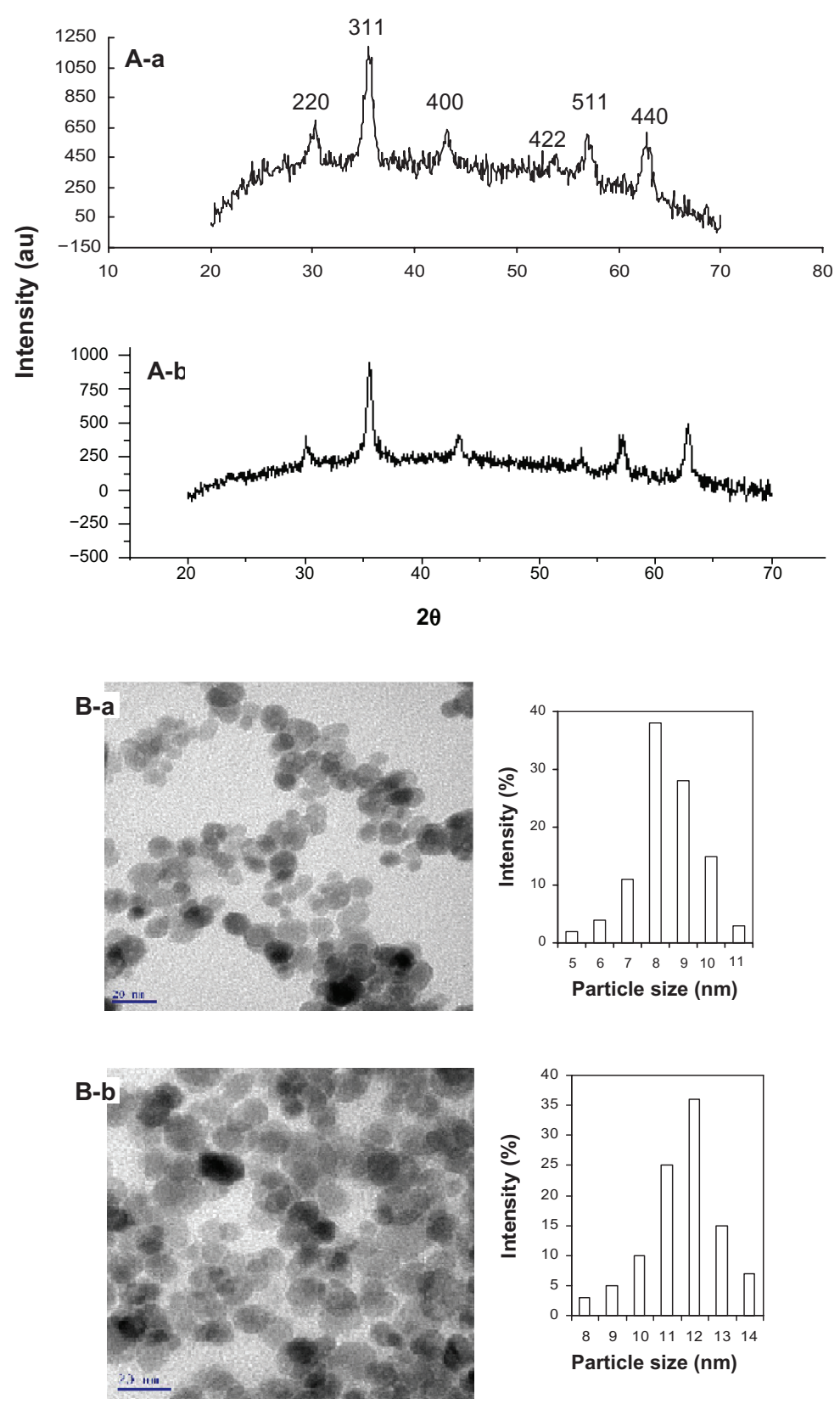

Figure 2 X-ray diffraction pattern (A) and transmission electron microscopic images (B) of bare-SPIONs (a) and PGA-SPIONs (b).

Abbreviations: SPIONs, superparamagnetic iron oxide nanoparticles; PGA-SPIONs, poly $(\gamma$-glutamic acid)-superparamagnetic iron oxide nanoparticles.

removal of positively-charged metal ions. A similar $\mathrm{pH}_{\mathrm{PzC}}$ value of $\sim 2.3$ was reported for carboxylic acid functionalized humic acid-SPIONs. ${ }^{14}$

\section{Metal removal at different $\mathrm{pH}$ levels}

A potential oral therapeutic drug is subjected to a range of $\mathrm{pH}$ conditions when administered into the human body, as gastrointestinal $\mathrm{pH}$ varies widely from highly acidic to slightly basic (pH 1-8) due to the presence of complex mixtures of different minerals and secretions. ${ }^{23,24}$ Additionally, the varying $\mathrm{pH}$ levels can affect the dissociation ability and structural conformation of polymer-coating material as well as metal speciation and stability of metal complex in a solution. ${ }^{30}$ Removal of lead or cadmium by PGA-SPIONs was poor at $\mathrm{pH} 1-2.5$ for the former and at $\mathrm{pH} 1-3$ for the latter. However, significant metal removal occurred afterwards reaching a plateau in the $\mathrm{pH}$ range from 4-8 (Figure 5).

From a physiological point of view, an efficient removal of metals could be attained under the gastrointestinal $\mathrm{pH}$ $5.5-7$ in the large intestine, 5.5 in the cecum/ascending colon, 6-6.5 in the duodenum, 6.8 in the distal colon, 7 in the small intestine, and 7-8 in the jejunum and ileum, but the metal 

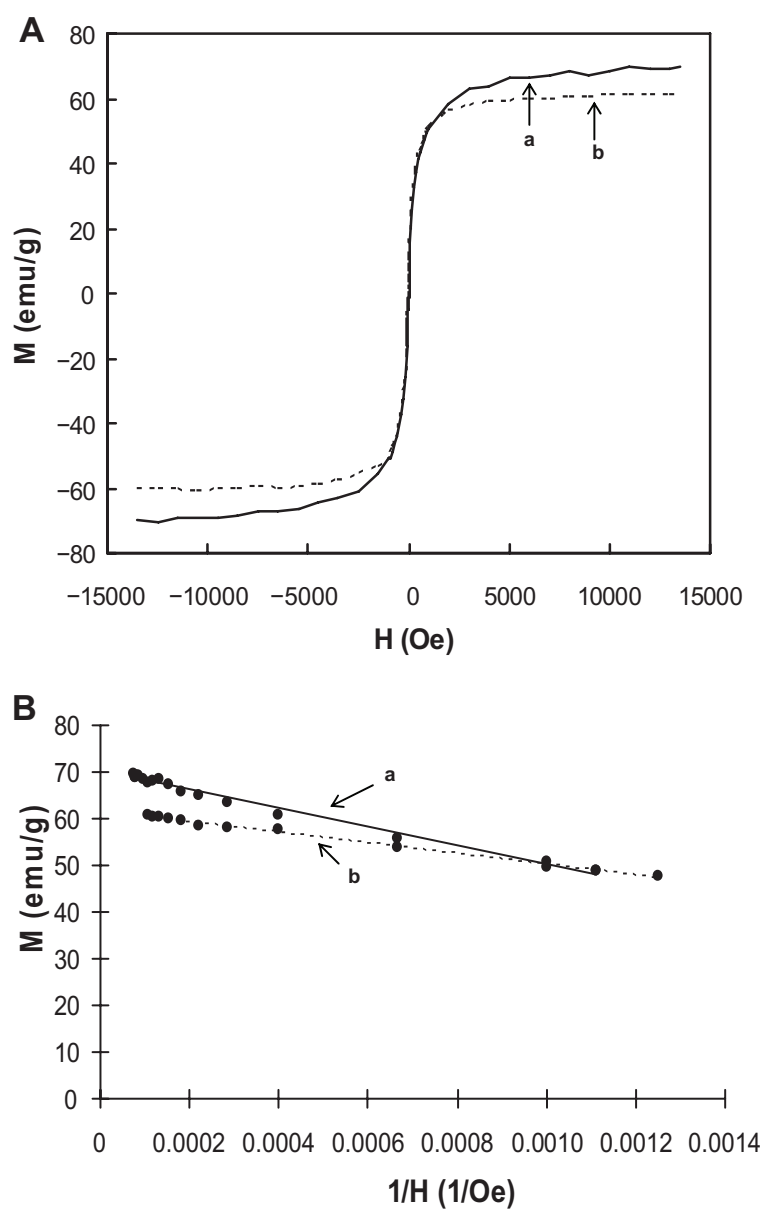

Figure 3 Magnetization curves showing magnetic moments as a function of applied magnetic field (A), and linear plots depicting the variation in magnetic moments as affected by reciprocal of applied magnetic field (B). (a) Bare-SPIONs; (b) PGA-SPIONs. Abbreviations: SPIONs, superparamagnetic iron oxide nanoparticles; PGA-SPIONs, poly $(\gamma$-glutamic acid)-superparamagnetic iron oxide nanoparticles.

removal efficiency remained inadequate at a stomach $\mathrm{pH}$ of $1-2.5$. Nevertheless, the small intestine is the main organ from where minerals and toxic compounds are absorbed. More importantly, the removal capacity of PGA-SPIONs towards lead or cadmium increased over a $\mathrm{pH}$ range of $1-4$ or remained stable at $4-8$, revealing that the bound metals were unleached under the gastrointestinal condition.

Following a rise in $\mathrm{pH}$ from 2.5 to 5 , both the lead and cadmium removal by PGA-SPIONs reached 86.91 and $20.54 \mathrm{mg} / \mathrm{g}$, respectively (Figure 5). This variation in removal capacity may be due to differences in electronegativity between lead (2.33) and cadmium (1.69). It is also possible that the high affinity of several labile hydrolysis and polymeric species formed by lead at high concentrations (such as $\left[\mathrm{Pb}_{4}(\mathrm{OH})_{4}\right]^{4+},\left[\mathrm{PB}_{3}(\mathrm{OH})_{5}\right]^{+}, \mathrm{Pb}(\mathrm{OH})^{+}$, and $\left.\mathrm{Pb}(\mathrm{OH})_{2}\right)$ may have resulted in a higher removal capacity than by simple ion exchange rules. ${ }^{24}$ As the coating material PGA contains numerous carboxyl groups, the solution $\mathrm{pH}$ and $\mathrm{pH}_{\mathrm{ZPC}}$

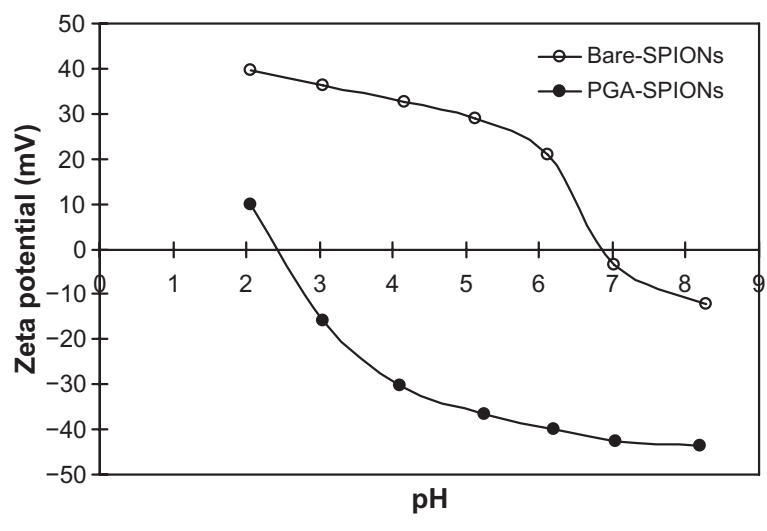

Figure 4 Zeta potential analyses of bare-SPIONs (a) and PGA-SPIONs (b) at different solution $\mathrm{pH}$.

Abbreviations: SPIONs, superparamagnetic iron oxide nanoparticles; PGA-SPIONs, poly $(\gamma$-glutamic acid)-superparamagnetic iron oxide nanoparticles.

of PGA-SPIONs should strongly influence the metal removal capacity. Consequently, the carboxyl groups on PGA-SPIONs remained unionized at $\mathrm{pH}<\mathrm{pH}_{\mathrm{ZPC}}$ of PGA-SPIONs ( $\mathrm{pH} 2.4$, Figure 4). However, a pronounced metal removal observed at $\mathrm{pH}>2.5$ for lead and $\mathrm{pH}>3$ for cadmium was probably caused by ionization of the carboxyl groups. In addition, the amide groups on PGA-SPIONs may also be responsible for metal removal and could be explained based on the Pearson's hard soft acid base (HSAB) principle. ${ }^{31}$ The HSAB principle depicts that a hard acid prefers to bind with a hard base through ionic interactions, while a soft acid binds with a soft

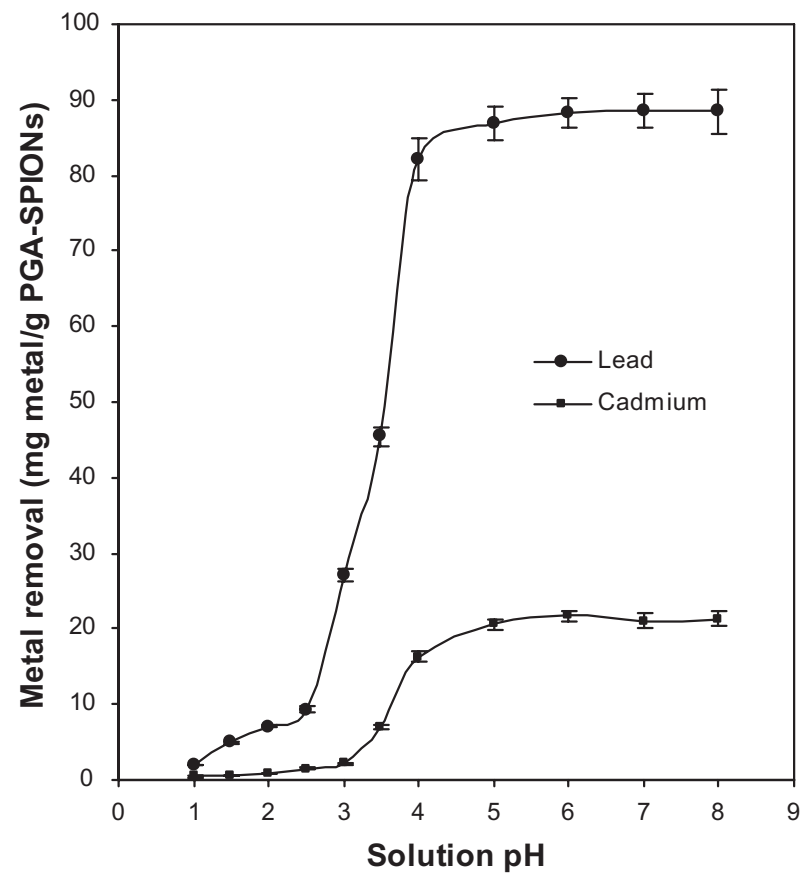

Figure 5 Effect of solution $\mathrm{pH}$ on lead and cadmium removal by PGA-SPIONs. Abbreviation: PGA-SPIONs, poly( $\gamma$-glutamic acid)-superparamagnetic iron oxide nanoparticles. 
base through covalent interactions. Given the classification of lead as a borderline acid and cadmium as a soft acid, their interaction with a hard base like carboxylate anions on PGA may not be possible unless through contribution from some other functional groups like amides, as pointed out by Siao et al. ${ }^{24}$

\section{Metal removal kinetics}

Rapid removal kinetics is therapeutically and diagnostically advantageous given that fast uptake could reduce both the residence time of metal and the amount absorbed in human body. ${ }^{9,24}$ Binding kinetics of lead or cadmium by PGA-SPIONs as shown in Figure 6A revealed a 92\%-95\% metal uptake within 1 minute and reached a peak within 5 minutes. Such rapid kinetic behavior of PGA-SPIONs suggests the absence of internal diffusion resistance during mass transfer, resulting in faster surface attachment, which is a critical factor for the treatment of acute metal intoxication. Similar rapid kinetics of $99 \%$ lead removal was shown within 1 minute by dimercaptosuccinic acidSPIONs, ${ }^{15}$ and $99 \%$ cadmium removal within 3 minutes by thiol-self-assembled monolayers on mesoporous silica. ${ }^{9}$ However, a relatively slower rate of $100 \%$ removal within 15 minutes was reported for lead, cadmium, mercury, and copper by humic acid-SPIONs, ${ }^{14}$ which was attributed to the slow site-site exchange of heavy metals in a disordered structure of the humic acid layer. To derive the removal rate and capacity, the kinetic data were fitted with two commonly used pseudo-first-order and

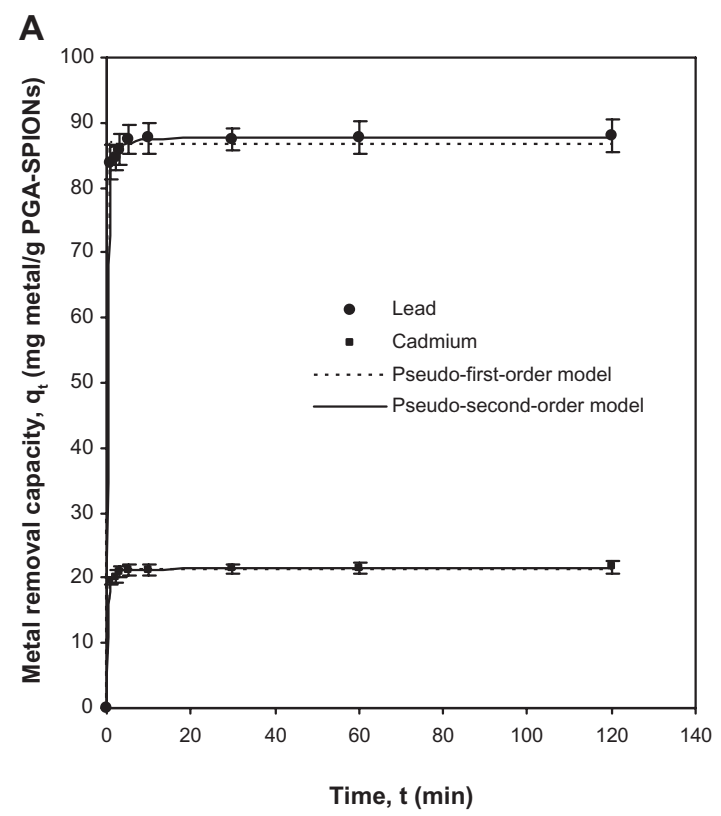

pseudo-second-order models, whose nonlinear forms are represented as given below:22,24

$$
\begin{gathered}
\mathrm{q}_{\mathrm{t}}=\mathrm{q}_{\mathrm{e}}\left[1-\exp \left(-\mathrm{k}_{1} \mathrm{t}\right)\right] \\
\mathrm{q}_{\mathrm{t}}=\frac{\mathrm{t}}{\frac{1}{\mathrm{k}_{2} \mathrm{q}_{\mathrm{e}}^{2}}+\frac{\mathrm{t}}{\mathrm{q}_{\mathrm{e}}}}
\end{gathered}
$$

where $\mathrm{k}_{1}(\mathrm{~L} / \mathrm{min})$ and $\mathrm{k}_{2}(\mathrm{~g} / \mathrm{mg} \cdot \mathrm{min})$ are the pseudo-firstorder and pseudo-second-order rate constants, respectively. Based on the correlation coefficient $\left(r^{2}\right)$, the pseudosecond-order model was shown to predict the kinetic data more precisely than the pseudo-first-order model, with the $r^{2}$ of lead and cadmium being 0.9997 and 0.9996 for the former, and 0.9973 and 0.9969 for the latter, respectively (Figure 6A). The good-fit by pseudo-second-order model suggests that the rate of lead or cadmium removal by PGA-SPIONs was controlled by chemical forces. ${ }^{22,24}$ The removal rate as determined by the pseudo-secondorder model was 0.212 and $0.424 \mathrm{~g} / \mathrm{mg} \cdot \mathrm{min}$ for lead and cadmium, respectively, while the removal capacity $\left(\mathrm{q}_{\mathrm{e}}\right)$ was 87.81 and $21.58 \mathrm{mg} / \mathrm{g}$.

\section{Metal removal isotherms}

The development of removal isotherms is pivotal for elucidating the interactions between heavy metals and PGA-SPIONs, as are the removal mechanism and removal affinity. ${ }^{22,24}$ More importantly, the modeling of equilibrium data provides the maximum removal capacity value

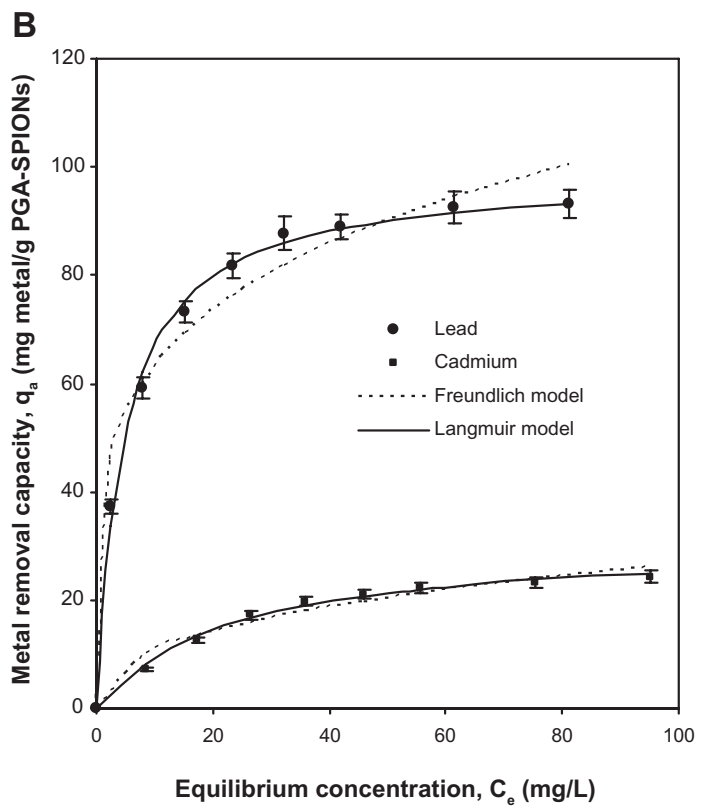

Figure 6 Removal kinetics (A) and removal isotherms (B) for lead and cadmium removal by PGA-SPIONs. Abbreviation: PGA-SPIONs, poly( $\gamma$-glutamic acid)-superparamagnetic iron oxide nanoparticles. 
for comparison with a wide variety of reported adsorbents. As the optimum $\mathrm{pH}$ for maximum lead or cadmium removal ranged from 4-8, the removal isotherms were developed at $\mathrm{pH} 5.5$ in order to be representative for most regions of the gastrointestinal environment (5.5-8), with the exception of the stomach (1-2.5). Figure 6B depicts the isotherm data obtained for the removal of lead or cadmium by PGASPIONs over a range of metal concentration varying from $10-100 \mathrm{mg} / \mathrm{L}$. Following an increase in metal concentration from $10-100 \mathrm{mg} / \mathrm{L}$, the amount of metal removed by PGASPIONs rose from 37.33-93.12 mg/g for lead and 7.14$24.35 \mathrm{mg} / \mathrm{g}$ for cadmium. By comparing these data with the classification of several isotherm shapes discussed by Giles et $\mathrm{al}^{32}$ the shape of the removal isotherm for lead or cadmium by PGA-SPIONs was designated as L-type, implying that the metal removal mechanism mainly involved chemical forces instead of physical interactions. Such L-type isotherms are actually Langmuir-type isotherms, signifying a high degree of removal at a low metal concentration. ${ }^{22}$

Two popular isotherms, namely, the Freundlich ${ }^{33}$ and the Langmuir, ${ }^{34}$ were used for modeling the isotherm data and establishing an appropriate correlation with minimum deviation. The non-linear representation of the isotherm models is shown below: 22,24

$$
\begin{gathered}
\mathrm{q}_{\mathrm{e}}=\mathrm{K}_{\mathrm{F}} \mathrm{C}_{\mathrm{e}}^{\frac{1}{\mathrm{n}}} \\
\mathrm{q}_{\mathrm{e}}=\frac{\mathrm{K}_{\mathrm{L}} \mathrm{C}_{\mathrm{e}}}{1+\mathrm{K}_{\mathrm{e}} \mathrm{C}_{\mathrm{e}}}
\end{gathered}
$$

where $\mathrm{K}_{\mathrm{F}}\left(\mathrm{L}^{\mathrm{n}} \mathrm{mg}^{1-\mathrm{n}} / \mathrm{g}\right)$ and $\mathrm{n}$ are the Freundlich constants denoting removal capacity and binding intensity, respectively, while $\mathrm{K}_{\mathrm{L}}(\mathrm{L} / \mathrm{g})$ is a product of $\mathrm{q}_{\mathrm{m}}(\mathrm{mg} / \mathrm{g})$ and $\mathrm{K}_{\mathrm{e}}(\mathrm{L} / \mathrm{mg})$, representing maximum removal capacity and binding energy or equilibrium constant, respectively. Of the two models tested, the Langmuir model $\left(r^{2}=0.9926-0.9965\right)$ described the isotherm data more precisely than the Freundlich model $\left(r^{2}=0.9597-0.9722\right)$, revealing monolayer binding of lead or cadmium on PGA-SPIONs without precipitation of metal ions at the studied conditions (Figure 6B). The maximum removal capacity $\left(\mathrm{q}_{\mathrm{m}}\right)$ values predicted by the Langmuir model was 98.70 and $31.13 \mathrm{mg} / \mathrm{g}$ for lead and cadmium, respectively, which are comparable to the values reported for humic acid-SPIONs (92.4 and $50.4 \mathrm{mg} / \mathrm{g})^{14}$ and wheat bran dietary fibers (31.04-128.80 and 15.55-70.88 mg/g), ${ }^{35}$ and much better than therapeutic drugs such as polyphepan (6.00 and $3.50 \mathrm{mg} / \mathrm{g}$ ), activated carbon (10.80 and $4.00 \mathrm{mg} / \mathrm{g}$ ), and penicillamine (17.70 and $3.20 \mathrm{mg} / \mathrm{g})$. However, a higher $\mathrm{q}_{\mathrm{m}}$ value was reported for trilon $\mathrm{B}(521.00$ and $57.80 \mathrm{mg} / \mathrm{g})$, unithiol (597.00 and $5.00 \mathrm{mg} / \mathrm{g}$ ), and sodium thiosulfate (492.90 and $328.80 \mathrm{mg} / \mathrm{g}$ ). ${ }^{36}$ Furthermore, the equilibrium constant $\left(\mathrm{K}_{\mathrm{e}}\right)$ values derived from the Langmuir model were 0.211 and $0.043 \mathrm{~L} / \mathrm{mg}$ for lead and cadmium, respectively. The binding intensity parameter (n) of the Freundlich model was higher for lead (4.5) than for cadmium (2.5), which is consistent with a larger $\mathrm{q}_{\mathrm{m}}$ value $(98.70 \mathrm{mg} / \mathrm{g})$ for the former. Moreover, the $\mathrm{n}$ value lying in the range of 1-10 denotes a favorable metal removal by PGA-SPIONs. ${ }^{24}$

\section{Metal removal at different ionic strengths}

It has been reported that some of the ion-exchange resins currently used as oral drugs for the removal of toxins suffer from swelling and shrinking due to variation in ionic strength, thereby reducing the therapeutic potential of such resin-based drugs. ${ }^{9}$ For instance, a cation-exchange resin sodium poly(styrenesulfonate) and cross-linked allylamine hydrochloride used for binding excess potassium and phosphate in the gastrointestinal tract were shown to impede their detoxification efficiency. ${ }^{9}$ Moreover, the ionic strengths in biological matrices (blood and urine) are likely to be greater than in most natural waters (river and ground water). Consequently, the ability of PGA-SPIONs to remove lead or cadmium was evaluated in the presence of varying ionic strengths (0.001-1 M) prepared by different concentrations of sodium acetate (Figure 7). Compared to control without sodium sulfate $(87.7 \mathrm{mg} / \mathrm{g})$, the removal capacity of lead by PGA-SPIONs remained unaltered in the $0.001 \mathrm{M}$ sodium acetate solution ( $88.1 \mathrm{mg} / \mathrm{g})$, but soared to $136.3,132.9$, and $110.1 \mathrm{mg} / \mathrm{g}$ in the $0.01,0.1$, and $1 \mathrm{M}$ solution, respectively, probably due to extra mobility gained by lead through competition with sodium ions. In contrast, for cadmium removal, the ionic strength varied from $0-0.01 \mathrm{M}$ sodium

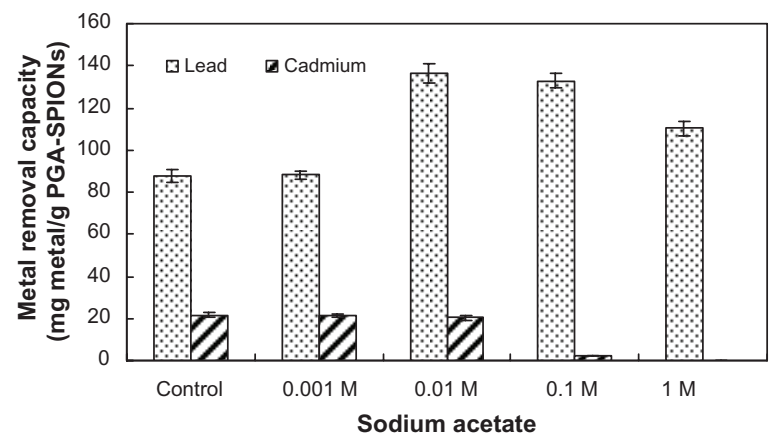

Figure 7 Effect of different ionic strengths at varying sodium acetate solution $(0.001 \mathrm{M}$ to I $\mathrm{M}$ ) on lead and cadmium removal by PGA-SPIONs.

Abbreviation: PGA-SPIONs, poly $(\gamma$-glutamic acid)-superparamagnetic iron oxide nanoparticles. 
acetate, and did not show any impact on the removal capacity (20.3-21.5 mg/g). However, a drastic decline occurred afterwards, as evident by a drop in removal capacity to 2.3 and $0 \mathrm{mg} / \mathrm{g}$ in 0.1 and $1 \mathrm{M}$ sodium acetate solution, respectively (Figure 7). Thus, the varying ionic strengths encountered in biological matrices may be unable to prevent the lead removal by PGA-SPIONs. Instead, the removal capacity was greatly enhanced.

\section{Lead or cadmium removal as affected by essential metals}

One of the major drawbacks of detoxification therapy is the ability of chelators to bind with some other essential metals like calcium and zinc, facilitating urinary excretion and ultimately causing deficiency in essential minerals. Take EDTA as an example; it can be used in chelation therapy, but it was found that calcium levels can exhibit a 2-fold reduction, while zinc levels can show an 18-fold reduction. ${ }^{10}$ Though this effect could be partly remedied by appropriate supplementation of essential minerals during detoxification therapy, the detoxification efficiency of chelating agents on target toxic metals may be reduced. ${ }^{24}$ Therefore, the effect of six essential metals including copper, zinc, iron, magnesium, calcium, and potassium on lead or cadmium removal by PGA-SPIONs was examined in a bisolute 1:1 mixture of lead/cadmium:essential metal (Figure 8).

Lead removal by PGA-SPIONs in the presence of four different levels $(5,25,50$, and $100 \mathrm{mg} / \mathrm{L})$ in a $1: 1$ mixture of lead/cadmium:essential metals showed no interference at $5 \mathrm{mg} / \mathrm{L}$ (Figure 8A). However, upon raising the concentration to $25 \mathrm{mg} / \mathrm{L}$, the lead removal dropped by $28.4 \%$ for copper, $20.2 \%$ for iron, $17.4 \%$ for potassium, $16.6 \%$ for zinc, $14.3 \%$ for calcium, and $8.2 \%$ for magnesium. Interestingly, at $50 \mathrm{mg} / \mathrm{L}$, the decrease in lead removal was only $9.8 \%$ for copper, $8.9 \%$ for calcium, $8.5 \%$ for potassium, $5.8 \%$ for zinc, and $5.3 \%$ for iron, but with a sharp rise ( $\sim$-fold) for magnesium when compared to the control without essential metals (Figure 8A). Likewise, the lead removal capacity climbed to a peak $(\sim 3$-fold $)$ in the presence of magnesium, zinc, iron, and copper at $100 \mathrm{mg} / \mathrm{L}$, but no significant difference was noted for calcium and potassium between 50 and $100 \mathrm{mg} / \mathrm{L}$. It may be postulated that the competition between essential metals and lead ions could enhance the mobility of lead ions for additional lead binding onto unoccupied sites of PGA-SPIONs. Unlike lead removal, the cadmium removal by PGA-SPIONs dropped sharply in the presence of essential metal ions, with the degree of interference following the following order: copper $>$ calcium $>$ magnesium $>$ iron $>$ zinc $>$ potassium (Figure 8B).
Being a monovalent ion, potassium showed a slight interference $(2.0 \%-2.6 \%)$ in cadmium binding at 5 and $25 \mathrm{mg} / \mathrm{L}$; however, this effect became more pronounced at $50 \mathrm{mg} / \mathrm{L}(23.1 \%)$ and $100 \mathrm{mg} / \mathrm{L}(93.6 \%)$. On the contrary, at 5,25 , and $50 \mathrm{mg} / \mathrm{L}$, the divalent ions reduced the cadmium binding to a larger extent, which amounted to 47.7, 85.7, and $96.6 \%$ for copper; $50.3,70.6$, and $88.4 \%$ for calcium; $42.0,69.7$, and $77.8 \%$ for magnesium; $38.4,56.5$, and $60.0 \%$ for iron; and 36.6, 54.6, and 58.4\% for zinc, respectively (Figure 8B).

Comparatively, PGA-SPIONs were more selective towards lead removal than cadmium, which may be explained based on the HSAB principle ${ }^{31}$ as described in the preceding section. Since cadmium is a soft acid, its interaction with a hard base like the carboxyl groups in PGA-SPIONs is unfavorable in the presence of hard acids like calcium, magnesium, and potassium as well as borderline acids like iron and zinc. This should also explain why iron and zinc were the least interfering essential metals noted in this study. Furthermore, for lead removal, an interference of only $\leq 20 \%$ was shown by all the essential metals except for copper $(28.4 \%)$. As pointed out previously, the high selectivity
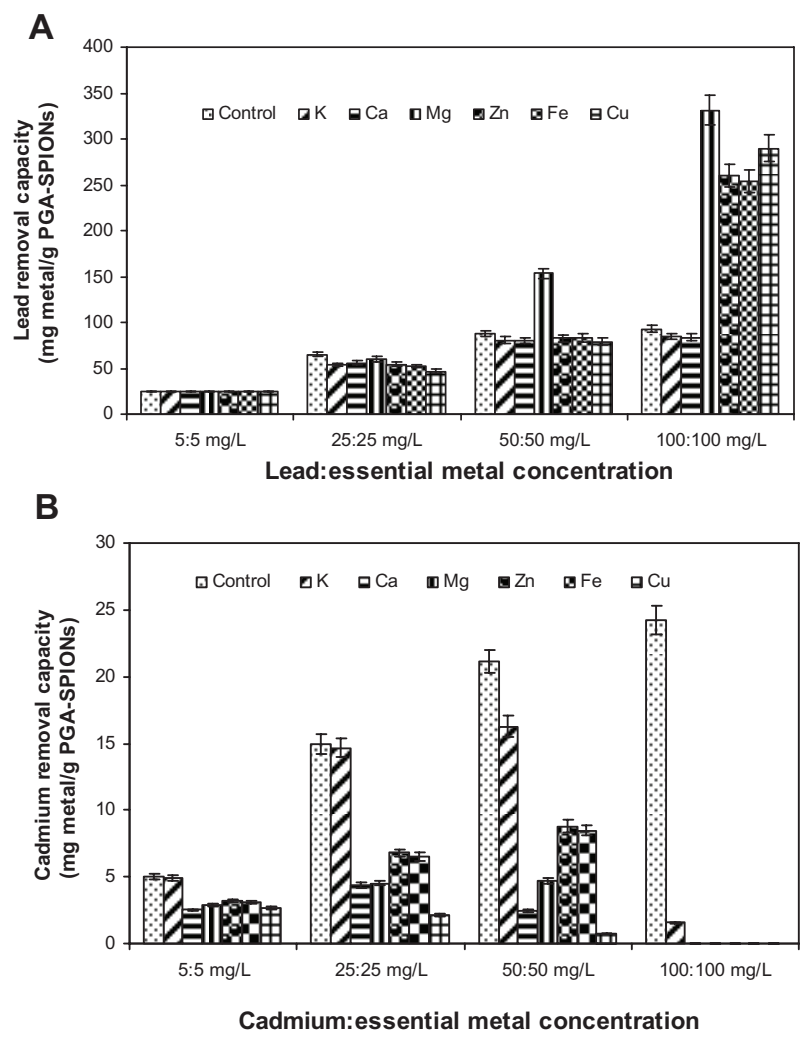

Figure 8 Effect of different essential metals on lead removal (A) and cadmium removal (B) by PGA-SPIONs.

Abbreviation: PGA-SPIONs, poly( $\gamma$-glutamic acid)-superparamagnetic iron oxide nanoparticles. 
of PGA-SPIONs towards lead can be attributed to the fact that lead is a borderline acid and a highly electronegative ion (2.33). Also, lead tends to form several hydrolyzed and polymeric species, all of which are more prone to binding with PGA-SPIONs.

\section{Metal removal from SGIF}

To learn about the impact of the gastrointestinal environment on metal removal by PGA-SPIONs, the effect of $\mathrm{pH}$ level and isotherm studies were carried out with SGIF prepared following the procedure described previously. Figure 9A depicts the influence of $\mathrm{pH}$ on the removal of lead or cadmium by PGA-SPIONs from both SGIF and deionized water for comparison. Obviously, the $\mathrm{pH}$ profile for SGIF followed a similar trend as the deionized water, with the lead removal capacity being higher at all $\mathrm{pH}$ levels for the former, which should be beneficial for in vivo application. Nevertheless, the lead removal capacity attained a plateau between $\mathrm{pH}$ 5-8 for SGIF and $\mathrm{pH}$ 4-8 for deionized water. Conversely, the cadmium removal capacity for SGIF showed a slightly lower value than that of the deionized water at all $\mathrm{pH}$ levels, which should be caused by sodium ions competing more effectively with cadmium for the active sites on the PGA-SPIONs (Figure 9A). Upon raising the $\mathrm{pH}$ level from 1 to 8 , the removal capacity of lead and cadmium from the SGIF climbed to 138.59 and $16.02 \mathrm{mg} / \mathrm{g}$, respectively, which was $56.4 \%$ higher and $25.0 \%$ lower than that for deionized water.

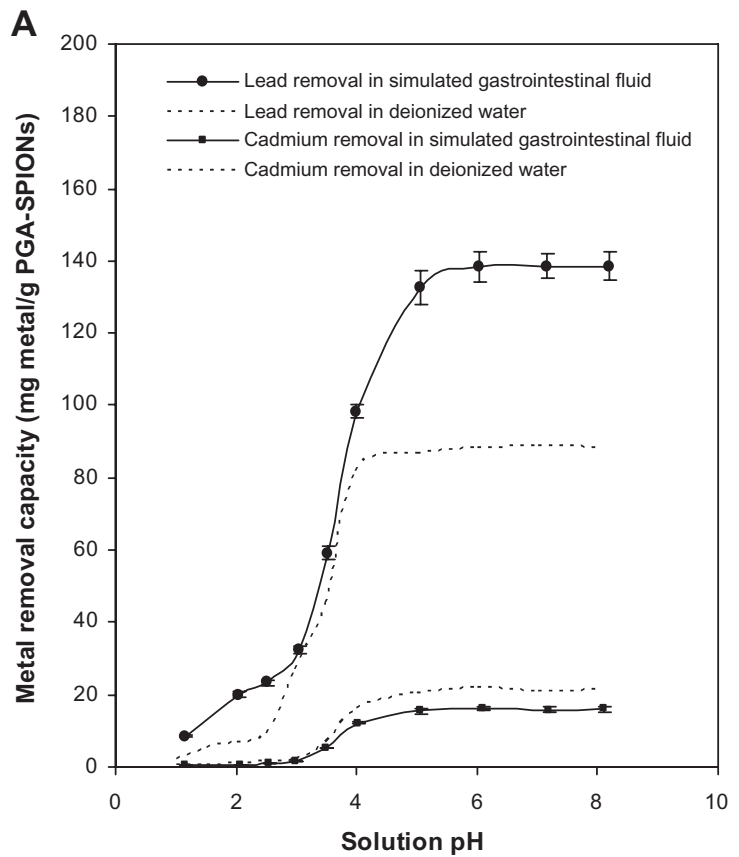

The high efficiency in lead removal by PGA-SPIONs across all $\mathrm{pH}$ levels for SGIF when compared to deionized water may be accounted for by the additional mobility gained by lead ions through the competition of sodium ions in SGIF. It is worth pointing out that sodium chloride $(0.03 \mathrm{M})$ was used as one of the ingredients in the preparation of SGIF. This tendency is further substantiated by a $55 \%$ enhancement in lead removal capacity in the presence $0.01 \mathrm{M}$ sodium acetate when compared to the control (without sodium acetate), as observed in the preceding study on effect of ionic strength. However, this effect was not observed for cadmium removal by PGA-SPIONs, which may be explained based on the HSAB theory. ${ }^{31}$ Accordingly, the sodium ions (a hard acid) should more readily bind with a hard base like the carboxyl groups on PGA-SPIONs when compared to cadmium (a soft acid), thereby preventing binding of cadmium on PGA-SPIONs. Based on this phenomenon, one would expect a similar trend to occur for lead removal as well, as lead is only a borderline acid. However, the high lead removal capacity by PGASPIONs in the presence of sodium ions may be attributed to its high electronegativity (2.33) as compared to sodium ions (0.93). Though cadmium possesses a higher electronegativity (1.69) than sodium, its lower binding on PGA-SPIONs should be due to strong acid-base interaction between sodium and carboxyl groups on PGA-SPIONs.

As the $\mathrm{pH}$ study showed different removal capacities for SGIF when compared to deionized water, the removal

B

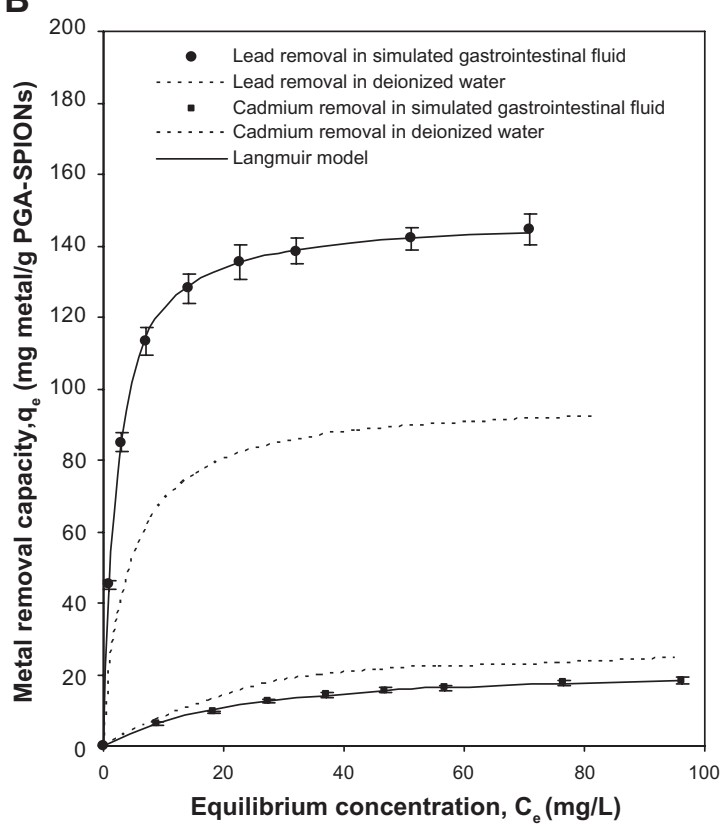

Figure 9 Solution $\mathrm{pH}$ variation (A) and isotherm (B) studies for removal of lead and cadmium by PGA-SPIONs from simulated gastrointestinal fluid. Abbreviation: PGA-SPIONs, poly $(\gamma$-glutamic acid)-superparamagnetic iron oxide nanoparticles. 
isotherms were developed for a range of metal concentrations $(10-100 \mathrm{mg} / \mathrm{L})$ in SGIF at $\mathrm{pH} 5.5$ and modeled with the Langmuir model (Eq 4) (Figure 9B). Metal removal isotherms obtained in SGIF are shown in Figure 9B along with those obtained in deionized water for comparison. Modeling of isotherm data with the Langmuir model provided a more precise fit than the Freundlich model, with the $r^{2}$ for the former being 0.9993 and 0.9967 for lead and cadmium, respectively (Freundlich model not shown) (Figure 9B). Based on the fitted Langmuir parameters, the maximum removal capacity $\left(\mathrm{q}_{\mathrm{m}}\right)$ and equilibrium constant $\left(\mathrm{K}_{\mathrm{e}}\right)$ obtained were $147.71 \mathrm{mg} / \mathrm{g}$ and $0.483 \mathrm{~L} / \mathrm{mg}$ for lead and $23.15 \mathrm{mg} / \mathrm{g}$ and $0.041 \mathrm{~L} / \mathrm{mg}$ for cadmium, respectively. Apparently, the isotherms for lead removal by PGA-SPIONs that developed for SGIF displayed a 1.5-fold increment in the $\mathrm{q}_{\mathrm{m}}$ value compared to that for deionized water, while a 0.3 -fold drop in $\mathrm{q}_{\mathrm{m}}$ value was observed for cadmium.

\section{Conclusion}

The present study demonstrated the potential of poly $(\gamma-$ glutamic acid)-coated superparamagnetic nanoparticles in the removal of heavy metals from a metal solution and simulated gastrointestinal fluid. Positively-charged PGASPIONs belonging to a magnetite structure were synthesized with a particle size of $11.7 \mathrm{~nm}$ and a magnetization value of $61.5 \mathrm{emu} / \mathrm{g}$. Efficient removal of heavy metals was shown at most of the gastrointestinal $\mathrm{pH}$ conditions, as illustrated with rapid removal kinetics (1-5 min) and good removal capacity $(147.71 \mathrm{mg} / \mathrm{g}$ for lead and $23.15 \mathrm{mg} / \mathrm{g}$ for cadmium). Unlike cadmium, different ionic strengths and essential metals showed no impact on lead binding by PGA-SPIONs, which is considered to be therapeutically beneficial for the selective removal of lead from the biological matrix, and thus can be applied for clinical treatment of metal intoxication.

\section{Acknowledgments}

The authors wish to thank the Electron Microscope Laboratory of Prof Tzong Jwo Jang at the School of Medicine, Fu Jen Catholic University, Taipei, Taiwan for technical assistance.

\section{Disclosure}

The authors report no conflicts of interest in this work.

\section{References}

1. Tandon SK, Singh S. Role of vitamins in treatment of lead intoxication. The Journal of Trace Elements in Experimental Medicine. 2000;13(3): 305-315.
2. Barbier O, Jacquillet G, Tauc M, Cougnon M, Poujeol P. Effect of heavy metals on, and handling by, the kidney. Nephron Physiol. 2005;99(4): $105-110$.

3. Sabolić I. Common mechanisms in nephropathy induced by toxic metals. Nephron Physiol. 2006;104(3):107-114.

4. Damek-Poprawa M, Sawicka-Kapusta K. Histopathological changes in the liver, kidneys, and testes of bank voles environmentally exposed to heavy metal emissions from the steelworks and zinc smelter in Poland. Environ Res. 2004;96(1):72-78.

5. Neri LC, Hewitt D. Aluminum, Alzheimer's disease, and drinking water. Lancet. 1991;338(8763):390.

6. Mikirova N, Casciari J, Hunninghake R, Riordan N. EDTA chelation therapy in the treatment of toxic metals exposure. Spatula DD. 2011; $1(2): 81-89$.

7. Wang C, Fang Y, Peng S, Ma D, Zhao J. Synthesis of novel chelating agents and their effect on cadmium decorporation. Chem Res Toxicol. 1999;12(4):331-334.

8. Flora SJ, Mittal M, Mehta A. Heavy metal induced oxidative stress and its possible reversal by chelation therapy. Indian J Med Res. 2008; 128(4):501-523.

9. Yantasee W, Rutledge RD, Chouyyok W, et al. Functionalized nanoporous silica for the removal of heavy metals from biological systems: adsorption and application. ASC Appl Mater Interfaces. 2010; 2(10):2749-2758.

10. Waters RS, Bryden NA, Patterson KY, Veillon CC, Anderson RA. EDTA chelation effects on urinary losses of cadmium, calcium, chromium, cobalt, lead, magnesium, and zinc. Biol Trace Elem Res. 2001;83(2):207-221.

11. Brown MJ, Wills T, Omalu B, Leiker R. Deaths resulting from hypocalcemia after administration of edetate disodium: 2003-2005. Pediatrics. 2006;118(2):e534-e536.

12. Nawirska A. Binding of heavy metals to pomace fibers. Food Chem. 2005;90(3):395-400.

13. Zhang N, Huang C, Ou S. In vitro binding capacities of three dietary fibers and their mixture for four toxic elements, cholesterol, and bile acid. J Hazard Mater. 2011;186(1):236-239.

14. Liu JF, Zhao ZS, Jiang GB. Coating $\mathrm{Fe}_{3} \mathrm{O}_{4}$ magnetic nanoparticles with humic acid for high efficient removal of heavy metals in water. Environ Sci Technol. 2008;42(18):6949-6954.

15. Yantasee W, Warner CL, Sangvanich T, et al. Removal of heavy metals from aqueous systems with thiol functionalized superparamagnetic nanoparticles. Environ Sci Technol. 2007;41(14):5114-5119.

16. Gupta AK, Gupta M. Synthesis and surface engineering of iron oxide nanoparticles for biomedical applications. Biomaterials. 2005;26(18): 3995-4021.

17. Chang YC, Chen DH. Preparation and adsorption properties of monodisperse chitosan-bound $\mathrm{Fe}_{3} \mathrm{O}_{4}$ magnetic nanoparticles for removal of $\mathrm{Cu}(\mathrm{II})$ ions. J Colloid Interface Sci. 2005;283(2):446-451.

18. Yavuz CT, Mayo JT, Yu WW, et al. Low-field magnetic separation of monodisperse $\mathrm{Fe}_{3} \mathrm{O}_{4}$ nanocrystals. Science. 2006;314(5801):964-967.

19. Song J, Kong H, Jang J. Adsorption of heavy metal ions from aqueous solution by polyrhodanine-encapsulated magnetic nanoparticles. J Colloid Interface Sci. 2011;359(5):505-511.

20. Ho GH, Ho TI, Hsieh KH, et al. $\gamma$-polyglutamic acid produced by Bacillus subtilis (natto): structural characteristics, chemical properties, and biological functionalities. Journal of the Chinese Chemical Society. 2006;53:1363-1384.

21. Shih IL, Van YT. The production of poly-( $\gamma$-glutamic acid) from microorganisms and its various application. Bioresour Technol. 2001; 79(3):207-225.

22. Inbaraj BS, Chien JT, Ho GH, Yang J, Chen BH. Equilibrium and kinetic studies on sorption of basic dyes by a natural biopolymer poly( $\gamma$-glutamic acid). Biochem Eng J. 2006;31(3):204-215.

23. Inbaraj BS, Chiu CP, Chiu YT, Ho GH, Yang J, Chen BH. Effect of $\mathrm{pH}$ on binding of mutagenic heterocyclic amines by the natural biopolymer poly( $\gamma$-glutamic acid). J Agric Food Chem. 2006;54(17): 6452-6459. 
24. Siao FY, Lu JF, Wang JS, Inbaraj BS, Chen BH. In vitro binding of heavy metals by an edible biopolymer poly( $\gamma$-glutamic acid). J Agric Food Chem. 2009;57(2):777-784.

25. Wang TL, Kao TH, Inbaraj BS, Su YT, Chen BH. Inhibition effect of poly $(\gamma$-glutamic acid) on lead-induced toxicity in mice. J Agric Food Chem. 2010;58(23):12562-12567.

26. Inbaraj BS, Kao TH, Tsai TY, Chiu CP, Kumar R, Chen BH. The synthesis and characterization of poly $(\gamma$-glutamic acid)-coated magnetite nanoparticles and their effects on antibacterial activity and cytotoxicity. Nanotechnology. 2011;22(7):075101.

27. The United States Pharmacopeia and National Formulary. 26th ed. Rockville, MD: United States Pharmacopeial Convention Inc.; 2003.

28. Inbaraj BS, Tsai TY, Chen BH. Synthesis, characterization and antibacterial activity of superparamagnetic nanoparticles modified with glycol chitosan. Science and Technology of Advanced Materials. 2012; 13:015002.

29. Shan Z, Yang WS, Zhang X, Huang QM, Ye H. Preparation and characterization of carboxyl-group functionalized superparamagnetic nanoparticles and the potential for bio-applications. J Braz Chem Soc. 2007;18(7):1329-1335.
30. He LM, Neu MP, Vanderberg LA. Bacillus licheniformis $\gamma$-glutamyl exopolymer: physiochemical characterization and U(VI) interaction. Environ Sci Technol. 2000;34(9):1694-1701.

31. Pearson RG. Hard and soft acids and bases. JAm Chem Soc.1963;85(22): 3533-3539.

32. Giles CH, MacEwan TH, Nakhwa SN, Smith D. Studies in adsorption. Part XI. A system of classification of solution adsorption isotherms, and its use in diagnosis of adsorption mechanisms and in measurement of specific surface areas of solids. J Chem Soc. 1960;111: 3973-3993.

33. Freundlich HMF. Über die adsorption in lösungen (Adsorption in solution), Zeitschrift fur Physikalische Chemi. 1906;57:384-470.

34. Langmuir I. The adsorption of gases on plane surfaces of glass, mica and platinum. J Am Chem Soc. 1918;40(9):1361-1403.

35. Ou S, Gao K, Li Y. An in vitro study of wheat bran binding capacity for Hg, Cd, and Pb. JAgric Food Chem. 1999;47(11):4714-4717.

36. Sergushchenko IS, Kovalev VV, Bednyak VE, Khotimchenko YS. A comparative evaluation of the metal-binding activity of low-esterified pectin from the seagrass Zostera marina and other sorbents. Russian Journal of Marine Biology. 2004;30(1):70-72.
International Journal of Nanomedicine

\section{Publish your work in this journal}

The International Journal of Nanomedicine is an international, peerreviewed journal focusing on the application of nanotechnology in diagnostics, therapeutics, and drug delivery systems throughout the biomedical field. This journal is indexed on PubMed Central, MedLine, CAS, SciSearch $\AA$, Current Contents ${ }^{\circledR} /$ Clinical Medicine,

\section{Dovepress}

Journal Citation Reports/Science Edition, EMBase, Scopus and the Elsevier Bibliographic databases. The manuscript management system is completely online and includes a very quick and fair peer-review system, which is all easy to use. Visit http://www.dovepress.com/ testimonials.php to read real quotes from published authors. 